\title{
Near-Death Experiences and Dissociation: Two Cases
}

\author{
William J. Serdahely, Ph.D. \\ Montana State University
}

\begin{abstract}
The near-death experience (NDE) literature has long chronicled the observation that out-of-body experiences (OBEs) lead to relief from physical and emotional pain. Researchers have suggested recently that the NDE may be viewed as dissociation. People who are physically or sexually abused, including those who have multiple personality disorder, often develop dissociative defenses and may well leave their bodies to achieve pain relief. This article presents two cases of NDEs that support the supposition that NDEs and OBEs may be a dissociative process.
\end{abstract}

Several years ago I reported the retrospective account of a near-death experience (NDE) triggered by sexual abuse of a pre-teenage girl by her father (Serdahely, 1987-88). In that same article, I noted the case of another woman who had had out-of-body experiences (OBEs) while being molested. She described her OBEs as a "safety valve" to escape the trauma of being abused.

Barbara Harris picked up on my suggestion of a connection between NDEs and child abuse and noted her impression that, in her subsequent work with near-death support groups and in the responses she's received to public presentations of her own NDE, "child abuse and incest survivors who have had NDEs are constantly popping up" (personal communication, 1987).

One of Harris's NDEs pertinent to her childhood physical and emotional abuse was discussed by Kenneth Ring (1984): during this NDE,

William J. Serdahely, Ph.D., is Professor of Health Science at Montana State University. Reprint requests should be addressed to Dr. Serdahely at the Department of Health and Human Development, Montana State University, Bozeman, MT 59717. 
at age 32, Harris had a life review in which she was able to see the abuse perpetrated on her at about the age of 4 or 5 . She had been harshly punished by her mother for wetting the bed, feeling unloved by both parents and ignored by her father (Harris and Bascom, 1990).

Ring and Christopher Rosing (1990) hypothesized that childhood abuse leads to subsequent adult NDEs by fostering the development of the "NDE-prone personality." Their research showed that childhood abuse and trauma, including sexual abuse, physical abuse or punishment, psychological abuse, neglect, or a negative home atmosphere, makes a person more likely to experience an NDE later in life.

Ring subsequently talked about NDEs as a form of dissociation to escape physical and psychological pain (Adolph and Taylor, 1992), a point I had alluded to earlier (Serdahely, 1987-88). Ring noted that people with the "encounter-prone personality"

are more likely to say that their childhoods were marked by patterns of various kinds of child abuse, trauma, and other forms of stress. They're people who, because of childhood trauma, are more likely to dissociate from ordinary reality and then tune in to other realities where they can feel safe. (Adolph and Taylor, 1992, p. 67)

Ring then more directly connected the concept of dissociation with NDEs by suggesting "that NDErs are dissociating from the trauma of being near death" (Mauro, 1992, p. 80). Harris, referring to her own NDE, concurred: "Yes, I am dissociating but I am also out of my body and I am someplace else" (Mauro, 1992, p. 81).

I have noticed some similarities between NDEs and multiple personality disorder (MPD), including the out-of-body experience common to both in response to pain (Serdahely, 1992b). Both NDErs and persons who have MPD may leave their bodies when the pain becomes unbearable; the former, for example, in conjunction with vehicular accidents or heart attacks, and the latter in conjunction with sexual abuse or torture. Ring and Rosing made a similar point when they wrote that abused children " 'tune into' other nonsensory realities where, by virtue of their dissociated state, they can feel safe regardless of what is happening to the body" (1990, p. 232).

Having interviewed several NDErs with MPD, I have noted the use of out-of-body experiences to gain relief from pain and view the $O B E$ as one stage of a continuum of dissociation. When victims get to the OBE stage of this continuum, they dissociate from the physical and/or psychological pain mediated by the nervous system by leaving the body. Harris's comment above about dissociating while out-of-body during her NDE fits into this continuum of dissociation, which includes the following stages: 
1. totally centered, "together," and completely in the body;

2. feeling fragmented and not "together," not totally present in the moment;

3. split, with co-consciousness of other personalities ("alters") in individuals with MPD;

4. split, without co-consciousness of "alters" in individuals with MPD;

5. not entirely in the body, at a little distance from the body; and

6. out-of-body.

Recently, one of my respondents described how she had left her body while making love with her estranged husband during a hiatus between acrimonious battles surrounding their divorce; she went out of body to separate herself from him. In light of Ring and Rosing's research, it is interesting to note that this woman had described being emotionally and physically abused as a Native American child by nuns in an Indian mission school. She said she recalled "not always being there" in the schoolroom as the nun verbally abused her or her Native American peers.

Another recent correspondent, Deena (a pseudonym), described her $\mathrm{OBE}$ at age 33 and subsequent personal transformation after 12 years of an emotionally and sometimes physically abusive marriage, the 12 years perhaps giving her what Ring and Rosing called the "NDE-prone personality." She described herself as like a cloud, or a vapor, or a fog while she was out-of-body, and said her return to her body was like a hand filling out a glove. During this reentry, she had the sensation of "needles and pins from the toes all the way up" her body.

But the connection between OBEs or NDEs and dissociation becomes even clearer given the following two extraordinary cases. In presenting these cases, I argue that MPD is not in itself pathological. It is the heinous torture and sadistic sexual abuse of a minor that are pathological; the dissociation, including splitting of consciousness, affiliated with MPD allows the victim to survive the torture and abuse. Ring made a similar point but did not go as far in writing:

It is normal to dissociate. We all dissociate to a degree and sometimes. Dissociation, except when it reaches an extreme, is not in itself pathological; in such cases, it is customary to speak of dissociative disorders. (1992, p. 143).

\section{Case 1: Kay}

Kay (a pseudonym) was incorrectly given an epidural anesthetic prior to a Caesarian section. This 24-year-old woman tried to tell the inattentive anesthesiologist she thought something had gone wrong 
with the injection. However, the physician did not believe her, at which time Kay commenced to have a near-death experience.

Kay next noticed that "light-consciousness" began to leave from every cell of her body. A ringing sound accompanied the withdrawal of this energy. All of the "light-consciousness" quickly concentrated in her heart. It then flowed from her heart through the top of her head, resulting in a kind of out-of-body experience in which Kay was floating near the operating room ceiling, looking down on the scene below. Kay unequivocally identified the "light-consciousness" as herself. She commented that "I'm still me" but without a physical body. In this out-ofbody state, Kay was able to hear fragments of conversations below her, and to see, think, and locomote as a "whitish, iridescent, light cloudy substance."

From the ceiling of the operating room, Kay then moved into a "clear tunnel" that separated her (and possibly protected her, she said) from a "black, dark void" surrounding her tunnel. The void was like "endless space," like "outer space." While in the tunnel as a white, cloudy "lightconsciousness," she met her "Higher Self." Her Higher Self was in a pale pink gown with a gold belt, and she found herself merging with this Higher Self, which she called a "spiritual body." At this point, Kay believed she was the real person she truly is; she described the merging of the "light-consciousness" with the Higher Self as "all me."

After undergoing a current life review and a review of approximately a thousand past lives in chronological order, in the company of her guardian angel, a group of about six kindred souls, and a "council" of three advisors, Kay decided to return to her physical body. Her return was instantaneous. She said she felt "light-consciousness" come through her head and the flow through her body filling out every cell. The filling out of the body was very fast compared to the withdrawal of energy from the body.

Asked if she experienced a separation from her spiritual body or Higher Self on the return, Kay replied she was not certain what happened to her Higher Self. She said that possibly her Higher Self separated from her and remained in a location above her physical body. Kay indicated she had been clinically dead for approximately 15 to 20 minutes.

\section{Case 2: Joan}

Conceived by a cult for the purpose of being its eventual priestess, at age 31 Joan (a pseudonym) had over 70 personalities. She had split many times due to the countless incidents of torture and sexual 
assaults she had endured literally since she was a neonate. While I have never been able to determine exactly how many OBEs and NDEs Joan has had in her lifetime, nevertheless in 13 interviews conducted thus far she has revealed a number of both.

On Halloween Day of 1991, Joan was abducted from the parking lot of a mall in a Southern state by a couple of cult members as she was getting out of her car. In March of 1992 Joan's therapist asked me to help Joan understand and interpret the OBE and the NDE she and her other personalities experienced as the result of the abduction and subsequent abuses perpetrated during the previous Halloween period. While the MPD literature uses the terms "personalities" and "alters" to refer to others in one's body, in this account I will use Joan's term of "selves" to refer to these others who shared her body.

At the very moment of her abduction in the parking lot, all of the 70some selves immediately went out-of-body to escape the expected imminent pain and abuse. These selves went to a "dusky" dimension, "like when the sun goes down," which Joan and her selves call "the space inbetween," a dimension between life and death, that is, between the physical body and the light. They were waiting in the "space inbetween," for the physical body to die and then for them to go on to the other side. While they were in the "space in-between," they decided they would not come back to the physical body.

Ring (1980) used the term "Higher Self" to indicate the divine, omniscient part of the NDEr, while the MPD literature generally uses Ralph Allison's term "Inner Self Helper" (Allison and Schwartz, 1980). Joan's Higher Self, which she calls "Mother," was with the other selves in the "space in-between" during this OBE. Mother drew a sketch for me of this particular OBE depicting all 70-some selves, including Mother herself, out-of-body, linked hand-in-hand with one another.

Mother's drawing showed them as if encapsulated by a cloud. Being cloudlike or vaporous while out-of-body, or of being enveloped in a cloudy substance, has been described by NDErs who presumably do not have MPD, including Deena and Kay described above, and Harris (Harris and Bascom, 1990). Mother's sketch also showed a cord connecting the cloud to Joan's physical body below it. In a letter, Mother likened this structure to an umbilical cord, and this too is reminiscent of the "silver cord" described by some NDErs (Grey, 1985; Morse and Perry, 1990).

At this point, none of the selves was in control of Joan's body. The cult ritual took place the night of the abduction; three more selvesthat is, three more personalities split off from Joan-resulted from that ritual. Then, at some point, Mother came into the body. The testimony is confusing on this point, but Mother seems to have taken control of 
Joan's body either to protect a new self who was being created concurrently in the "space in-between," or to keep Joan's body alive: Mother stated that Joan's "mission in life had not been completely fulfilled yet," similar to what NDErs often say about their reason for returning to their bodies.

The body was then transported by three thugs to be given over to a cult leader. To facilitate the transfer, the body was heavily sedated, possibly with the hypnotic drug Halcion. As the thugs were waiting for the cult leader to arrive, one of them sexually assaulted the body. Mother was still in control of the body at this time and felt the abuse from the assault. More drugs were put into Joan's mouth. The body was then left in the woods where the assault took place, the thugs departing with the cult leader's failure to show.

During this assault, all of the selves except Mother stayed in the "space in-between." At this point, a large hand, accompanied by "so much light and brightness" that was "not hurtful to the eyes" penetrated the dusky region. This, Joan said, was God's hand taking hold of the hand of Kristina, one of Joan's selves. Kristina-2, a new self, then separated from Kristina and continued to hold onto God's hand as God and Kristina-2 went into the white light. Here again the experience is reminiscent of "the hand of God" reaching for NDErs who are not known to have MPD (Morse and Perry, 1990).

God then asked, "Are you all right?", making eye contact with Mother, who is Joan's Higher Self or Inner Self Helper, the divine part of the individual that is the connection to God. God then told Kristina-2, "We'll be going back soon. You must return; you're not finished." Kristina-2 told me, in a voice, language, and sentence structure quite different from Joan's, that she next saw clouds and palm trees rushing up to her, and then found herself in the body and in control of it. She found a bag of clothes next to the body, and told me they were not her clothes; presumably, they were Joan's.

A light, like a "flashlight," appeared ahead of her, leading her out of the woods. Kristina-2 was found walking along a highway by a law enforcement officer and taken to a local hospital. There she had an allergic reaction to a dye she was given for abdominal $x$-rays and had a seizure and cardiac arrest, which brought all the other selves back into the body from the "space in-between."

To summarize this account, due to previous, copious traumata starting from birth, Joan had split into 70-some selves. She was in contact with her Higher Self ("Mother") as a result of the magnitude of the cumulative abuse (Serdahely, 1992a). All of the selves left the body in anticipation of yet another abusive ritual about to take place, and 
while they were in the dusky "space in-between," a new self was created. This new self, Kristina-2, had a light experience much like an NDE, walking hand-in-hand with God in bright, white light and receiving communication from God. Taking control of the physical body, Kristina-2 then had a post-NDE paranormal event in which she followed a light out of unfamiliar woods, reminiscent of the paranormal events that follow NDEs (Grey, 1985; Ring, 1984). Thus while 70-some selves were out-of-body, one self was having an NDE.

\section{Discussion}

In a previous article on the similarities between near-death experiences and multiple personality disorder, I concluded that NDEs and MPD may be "variants of the very same experience, variations of the same phenomenological pattern" (Serdahely, 1992b, p. 37). That phenomenological pattern can now be identified as dissociation (Ring, 1992). Both Kay and Joan dissociated in part by means of their respective out-of-body and near-death experiences.

Deena's sensation, described above, of filling up the body on the return from an OBE is not new to students of near-death research. But what may be new is the opposite experience of leaving the body, as described above by Kay. Kay's dissociation from her incompetently anesthetized body began with the "light-consciousness" energy emerging from every cell and coalescing in her heart. Her dissociation continued as the cloudy substance of "light-consciousness" that was Kay left her physical body through the top of her head, and finally as she merged with her Higher Self. At that point, Kay believed she was all of who she is, that is, "all me."

Deena's experience has relevance also with respect to Joan's dissociation, which included an OBE and an NDE: Deena had endured 12 years of emotional and physical abuse, and Joan more than 30 years of abuse. Like a number of my respondents who related NDEs, Joan and her selves dissociated from a body about to be tortured and abused yet another time by the cult. Ring wrote that "an individual [with] a history of childhood abuse and trauma," when faced with trauma or shock later in life, is "more likely . . . spontaneously to 'flip' into" nonordinary realities $(1992$, p. 146$)$, which is exactly what happened to Joan and her other selves at the moment of abduction.

Prior to the OBE and NDE described above, Joan had many times before dissociated from the pain inflicted on her by splitting into more than $\mathbf{7 0}$ selves. I hypothesize that what is splitting for Joan and for 
others who have MPD is the "light-consciousness," that cloudy, white energy of consciousness and intelligence that leaves the body at the inception of an NDE. Joan's "light-consciousness," if you will, split again and again to cope with unthinkable atrocities and inconceivable tortures. This splitting allowed at least some of the selves to dissociate from the events that caused the split.

Joan's dissociation left the selves in a "void" with a strong determination never to come back to that tortured physical body. The void has been described by near-death experiencers (Morse and Perry, 1990), and Sandra Ingerman (1991) wrote about going on shamanic journeys into a void to retrieve soul parts. Stephen Levine (1984) referred to a "mezzanine" where the consciousness of people in comas may go, a place between ordinary reality and the light. Fourteen NDErs interviewed by Michael Sabom described entering a "dark region or void" (1982, pp. 41-43).

Another of my respondents described a place that sounds quite similar to the void mentioned by these other researchers and by Joan. Diane (a pseudonym) had two NDEs, the first a warm, joyful, and beautiful experience with a loving, wonderful presence in a meadow of unearthly colors. Her second NDE came 12 years later while in a coma; this time there were no colors, only gray, like a gray mist or fog. The loving presence was not in this gray dimension, but deceased relatives and other persons were. Diane believed she was in this grayness for a couple of days, the duration of her coma. She said this grayness was like a "plateau," a place to wait until it was her time to die, to wait to move on to the "environment of colors" or the light. Likewise, Joan and her selves were waiting in the "space in-between" or the void for the other side to open up; they were waiting for their time to die and enter the light.

Joan's dissociation with respect to her OBE and NDE was further evidenced by her contact with her Higher Self or Inner Self Helper, Mother. Unlike Kay, Joan did not merge with her Higher Self, but remained separate. Being separate from Mother allowed Mother to protect and to provide loving help for Joan's many selves. The separation and contact between Joan and Mother seems to be an indication of the need for loving help from the other side (Serdahely, 1992a).

Joan and her selves remained in the dark void, whereas Kay, having merged with her Higher Self while in a "clear" tunnel that kept her from the surrounding darkness, traveled on to the dimension of the white light. After Kay's return to her physical body, she said, her Higher Self most likely remained in the nonordinary reality somewhere above her body. Kay's return to her physical body as "light- 
consciousness" without her Higher Self suggests a reassociation with her body following its dissociation.

In a letter, Joan summarized what dissociation was like for her as someone who has MPD. Her "dissociative process," as she called it, has the following steps:

1. "daydreaming - whole self present";

2. integrated with some or many of the selves;

3. "space sharing" with another self, where two selves simultaneously control the body;

4. "watching, listening, and feeling" while in the body but with another self in control of the body; co-consciousness with other selves;

5. no co-consciousness with other selves; only the Higher Self is able to contact Joan;

6. out of body, going to the "space in-between" or to the void; and

7. "contact with [the] other side," with the light.

Joan's "dissociative process" is similar to what Harris described as her "dissociating" (Mauro, 1992, p. 81).

At the time of this writing, Joan has now blended or integrated her selves to a considerable extent, with Joan, the birth personality, in control of the physical body. The integration can be seen as the opposite of dissociation, that is, a willingness or capacity to associate with the physical body, even though that may be painful at times.

\section{Summary}

Some of the literature on multiple personality disorder has indicated that dissociation may be used to cope with pain (Ross, 1989). And some of the near-death literature has suggested that the out-of-body stage of an NDE provides the experiencer with relief from pain (Moody and Perry, 1988; Serdahely and Walker, 1990). Ring and Rosing (1990) have implied, and Ring (1992) and Harris (Mauro, 1992) have each proposed, that the NDE and the OBE are ways to dissociate. I suggest that the $\mathrm{OBE}$ is one stage of a continuum of dissociation from a physical body.

As mentioned above, NDErs find relief from pain by having an $\mathrm{OBE}$, and their pain returns when they return to their painful body. Hence the various degrees of dissociation may be thought of as increasing the distance from a painful body, that is, of dissociating from the painful 
body. The antithesis of dissociation then is association, being able to associate with a physical body, the end point of which is being totally centered in the body.

The cases of Kay and Joan corroborate the supposition that NDEs and OBEs are part of the process of dissociation. These two experiencers dissociated from a physical body that was, in Joan's case, too physically and/or emotionally painful to be in, and in Kay's case, too physiologically close to death to sustain life.

\section{References}

Adolph, J., and Taylor, P. (1992). The cosmic connection. New Age Journal, 11, 66-69 and 122.

Allison, R., and Schwartz, T. (1980). Minds in many pieces. New York, NY: Rawson, Wade.

Grey, M. (1985). Return from death: An exploration of the near-death experience. London, England: Arkana.

Harris, B., and Bascom, L. (1990). Full circle: The near-death experience and beyond. New York, NY: Pocket Books.

Ingerman, S. (1991). Soul retrieval: Mending the fragmented self. San Francisco, CA: Harper San Francisco.

Levine, S. (1984). Meetings at the edge. Garden City, NY: Anchor Press.

Mauro, J. (1992). Bright lights, big mystery. Psychology Today, 25, 54-57 and 80-82.

Moody, R.A., Jr., and Perry, P. (1988). The light beyond. New York, NY: Bantam.

Morse, M., and Perry, P. (1990). Closer to the light: Learning from the near-death experiences of children. New York, NY: Villard.

Ring, K. (1980). Life after death: $A$ scientific investigation of the near-death experience. New York, NY: Coward, McCann, and Geoghegan.

Ring, K. (1984). Heading toward omega In search of the meaning of the near-death experience. New York, NY: William Morrow.

Ring, K. (1992). The Omega Project: Near-death experiences, UFO encounters, and mind at large. New York, NY: William Morrow.

Ross, C. (1989). Multiple personality disorder: Diagnosis, clinical features, and treatment. New York, NY: John Wiley.

Sabom, M. (1982). Recollections of death: A medical investigation. New York, NY: Harper and Row.

Serdahely, W. (1987-88). The near-death experience: Is the presence always the higher self? Omega, 18, 129-134.

Serdahely, W. (1992a). Loving help from the other side: A mosaic of some near-death and near-death-like experiences. Journal of Near-Death Studies, 10, 171-182.

Serdahely, W. (1992b). Similarities between near-death experiences and multiple personality disorder. Journal of Near-Death Studies, 11, 19-38.

Serdahely, W., and Walker, B. (1990). The near-death experience of a nonverbal person with congenital quadriplegia. Journal of Near-Death Studies, 9, 91-96. 